\title{
Determinantes da pobreza nas Regiões Metropolitanas do Brasil no período de 1995 a 2009
}

Poverty determinants in Brazilian Metropolitan Areas from 1995 to 2009

\begin{abstract}
The objective of this paper is to analyze the impact of growth and inequality on poverty in the metropolitan areas of Brazil. For both factors we use Shapley's temporal and spatial decomposition, through a methodology proposed by Shorrocks (1999). We analyzed data obtained from PNAD from 1995 to 2009. The measurement of poverty is treated with the family of Foster-Greer-Thorbecke (FGT) indices, using one poverty line. The results of the annual analysis showed little change in poverty levels in the period 19952003. The following period, 2004-2009, shows a declining trend in poverty indicators for all metropolitan areas and the growth component is the main determinant of this trend. With regards to the spatial analysis of decomposition of poverty, there are changes in the spatial pattern, with decreasing levels of poverty differences between the country's metropolitan areas.
\end{abstract}

\section{Keywords}

poverty; inequality; growth.

JEL Codes D3; D31.

\author{
Douglas Mesquita Carneiro \\ Pontifícia Universidade Católica do Rio Grande do Sul \\ Izete Pengo Bagolin \\ Pontifícia Universidade Católica do Rio Grande do Sul \\ Silvio Hong Tiing Tai \\ Pontifícia Universidade Católica do Rio Grande do Sul
}

\section{Resumo}

O objetivo deste artigo é analisar o impacto do crescimento e da desigualdade de renda na evolução da pobreza nas regiões metropolitanas do Brasil. Para tanto, aplica-se à decomposição temporal e espacial de Shapley, por meio da metodologia proposta por Shorrocks (1999). Utilizam-se dados da Pesquisa Nacional por Amostra de Domicílio (PNAD) de 1995 a 2009. A mensuração da pobreza é tratada com base na familia de indicesFoster-Greer-Thorbecke (FGT), usando uma linha de pobreza de $R \$ 140,00$. Os resultados da análise anual mostraram pouca variação nos niveis de pobreza no periodo de 1995 a 2003. O período seguinte, de 2004 a 2009, apresenta tendência de queda nos indicadores de pobreza para todas as regiões metropolitanas, sendo o componente crescimento o principal determinante de tal trajetória. A análise espacial de decomposição da pobreza mostra alterações no padrão espacial, com diminuição das diferenças dos niveis de pobreza entre as regiões metropolitanas do país.

\section{Palavras-chave}

pobreza; desigualdade de renda; crescimento.

Códigos JEL D3; D31. 


\section{Introdução}

A literatura que aborda questões relativas ao desenvolvimento econômico tem dado grande importância ao fato de que qualquer conjunto de ações que visem ao crescimento econômico de um país ou região deve vir acompanhado de uma melhora nas condições de vida dos habitantes, especialmente dos mais pobres (Manso; Barreto; Tebaldi, 2006). Por esse motivo, analisar o impacto do crescimento sobre a pobreza e sobre as condições de vida da população é um tema relevante tanto para os formuladores de políticas quanto para a população como um todo.

A questão da pobreza e dos fatores a ela vinculados começa a ser mais bem investigada a partir do momento em que as questões macroeconômicas ligadas à estabilização da economia brasileira deixam de ser o tema principal nos debates econômicos. Rocha (2010) reforça que o estudo da pobreza começou a receber maior atenção não somente graças à nova ênfase dada ao tema pela academia, mas também pelo interesse das instituições internacionais relacionadas ao desenvolvimento econômico.

Apesar de o Brasil apresentar elevada proporção de pobres, ${ }^{1}$ esse indicador tem apresentado tendência de queda ao longo dos últimos anos. Segundo dados do Instituto de Pesquisa Econômica Aplicada (IPEA), a proporção de pobres no país diminuiu de $35,08 \%$, em 1995, para $21,42 \%$, em 2009. Isso indica que a quantidade de indivíduos abaixo da linha de pobreza tem diminuído ao longo do tempo. Além da trajetória declinante da pobreza nos últimos anos, verifica-se queda nos níveis de desigualdade de renda. De acordo com dados do IPEA, ${ }^{2}$ o coeficiente de Gini passou de 0,601, em 1995, para 0,543, em 2009.

Ao se analisar a pobreza sob a ótica da privação de renda, a literatura distingue dois macrodeterminantes imediatos: o crescimento econômico e a distribuição de renda. Em outras palavras, a pobreza é afetada pela "escassez de recursos agregados e má distribuição dos recursos existentes" (Araújo, 2007, p. 5).

1 Medida definida para este estudo como sendo o percentual de pessoas na população total com renda per capita inferior à linha de pobreza de $R \$ 140,00$. A utilização do conceito unidimensional de privação de renda, aqui utilizado, traz consigo simplificações por se tratar unicamente da renda, uma vez que a pobreza é considerada como um fenômeno multidimensional. Entretanto, considera-se que a renda tende a ser correlacionada com diversos aspectos do bem-estar, já que, quanto mais elevada a renda do indivíduo, maior tende a ser sua capacidade de acesso a bens e serviços geradores de bem-estar.

2 Instituto de Pesquisa Econômica Aplicada. Disponível em: www.ipeadata.gov.br. 
O objetivo deste artigo é analisar o impacto dos macrodeterminantes na evolução da pobreza nas regiões metropolitanas do Brasil. O estudo utiliza dados da Pesquisa Nacional por Amostra de Domicílio (PNAD) do período de 1995 a 2009. Busca-se assim compreender e explicar as variações na pobreza em termos de diferenças de renda per capita e desigualdade de renda. Para tanto, utiliza-se a decomposição temporal e espacial de Shapley, metodologia essa proposta por Shorrocks (1999). A mensuração da pobreza é tratada com base na família de índices Foster-Greer-Thorbecke (FGT), com a utilização de uma linha de pobreza que remete à linha político- administrativa ${ }^{3}$ adotada pelo governo federal de R $\$ 140,00$.

Além desta seção introdutória, o restante do artigo está dividido em quatro seções. A seção 2 apresenta uma breve revisão da literatura utilizada, dando ênfase à aplicação de técnicas de decomposição de variação da pobreza e seus respectivos resultados. A terceira seção descreve a metodologia utilizada, bem como os dados empregados neste estudo. A seção 4 mostra uma análise descritiva da pobreza e os principais resultados encontrados nos exercícios de decomposição espacial e temporal. Por fim, na última seção, são apresentadas as considerações finais.

\section{Os macrodeterminantes da variação da pobreza}

A análise do comportamento da pobreza tem sido objeto de muitos estudos nos últimos anos. Sua importância se deve ao fato de que um melhor entendimento da sua dinâmica tende a ter um impacto positivo na condição de vida da população. Este artigo considera a mensuração da pobreza sob o âmbito unidimensional, conceito que distingue os pobres dos não pobres através da renda monetária. Os estudos que explicam a variação da pobreza por meio de seus dois macrodeterminantes imediatos, crescimento econômico e redução da desigualdade, têm ganhado destaque na literatura (Matias; Salvato; Barreto, 2010).

A forma como o crescimento da renda afeta diretamente os níveis de pobreza é de fácil entendimento. O aumento na renda dos indivíduos inseridos abaixo de uma determinada linha de pobreza faz com que esses deixem a condição de pobreza. Entretanto, a relação positiva entre desigual-

3 Ministério do Desenvolvimento Social e Combate à Fome. Disponível em: www.mds.gov.br. 
dade de renda e pobreza pode ocorrer de diferentes maneiras. Segundo Todaro e Smith (2009), existem três principais explicações para o impacto da distribuição de renda nos níveis de pobreza, descritos na sequência.

Em primeiro lugar, uma economia com alta desigualdade de renda tende a ser ineficiente, já que nessas sociedades apenas uma pequena parcela da população tem acesso a empréstimos e a outras formas de crédito. Além disso, sociedades altamente desiguais têm baixa taxa de poupança e, consequentemente, menos investimentos. Em segundo lugar, a estabilidade social e a solidariedade são prejudicadas pela extrema desigualdade, uma vez que a elevada desigualdade econômica favorece o poder político dos ricos em detrimento dos mais pobres. Finalmente, a desigualdade de renda é vista como injusta, pois faz com que os indivíduos não possuam as mesmas oportunidades de acesso a bens e serviços.

As técnicas de decomposição da variação da pobreza mostram que o nível de pobreza pode se alterar tanto em razão de alterações na renda média como também de mudanças nos níveis de desigualdade. Dessa forma, pode-se separar as medidas de pobreza em dois componentes: crescimento e redistribuição. $O$ componente crescimento 4 é definido através de uma mudança no índice de pobreza provocada por alterações na renda média que mantém a distribuição da renda constante em um nível de referência. Já o componente distribuição refere-se a mudanças na medida de pobreza por causa de alterações na desigualdade de renda, mantendo a renda média constante em um nível de referência.

Datt e Ravallion (1992) foram dois dos pioneiros na abordagem de decomposição de índices de pobreza em componentes de crescimento e desigualdade. Outros autores, como Kakwani (1997) e Shorrocks (1999), também analisaram a pobreza sob a ótica unidimensional da privação de renda, propondo diferentes metodologias de decomposição.

No contexto internacional, tais análises, aplicadas a diferentes locais, vão ao encontro de outros trabalhos que aplicam essas metodologias (Baye, 2004; Mazumdar; Son, 2002; Zhang; Wan, 2005). Há uma convergência nessa literatura que indica predominância do componente crescimento (renda média).

No Brasil, os exercícios de decomposição da variação da pobreza também apontam o componente crescimento como o principal macrodetermi4 Neste trabalho, usa-se o componente crescimento e o componente crescimento da renda como sinônimos. 
nante da pobreza. Marinho e Soares (2003) utilizam a metodologia proposta por Datt e Ravallion (1992) para explicar as variações da pobreza nos estados brasileiros, de 1985 a 1999. Os resultados encontrados apontam para um efeito renda (crescimento) superior ao efeito da desigualdade na maioria dos estados. Em outras palavras, a variação da pobreza é mais bem explicada pela variação da renda.

Para esclarecer as variações na pobreza das 12 mesorregiões mineiras, no período de 1970 a 2000 e nos subperíodos de 1970-1980, 1980-1991 e 1991-2000, Araújo (2007) utiliza a decomposição de Shapley, proposta por Shorrocks (1999). Os resultados encontrados mostram que o efeito crescimento da renda foi o fator predominantemente responsável tanto pela queda na pobreza na primeira e na última décadas quanto pelo aumento na década intermediária.

No que tange exclusivamente ao Brasil, porém, alguns autores questionam os resultados encontrados em exercícios de decomposição. Esses autores apontam que o principal problema não está na escassez de recursos, e sim na má distribuição desses. Em outras palavras, a desigualdade de renda seria o principal determinante da pobreza (Barros et al., 2006; Barros; Henriques; Mendonça, 2000; Barreto; França; Oliveira, 2008). De acordo com Rocha (2006), a incidência de pobreza absoluta no Brasil é resultado da forte desigualdade na distribuição da renda. O presente estudo se diferencia dos até então verificados por analisar o comportamento da pobreza nas regiões metropolitanas do Brasil mediante a decomposição de Shapley, subdividindo a análise em períodos anuais.

De acordo com Shorrocks (1999), a decomposição de Shapley tem como uma das vantagens o fato de possibilitar a verificação da variação dos determinantes no ano-base e no ano final em conjunto. Shorrocks (1999) observa que as decomposições que apresentam um resíduo associam os efeitos crescimento e redistribuição com a mudança marginal na pobreza a partir da situação ano-base somente, assim não mensuram a mudança observada na pobreza, sendo necessária a introdução de um termo residual de equação de decomposição.

Araújo (2007) aponta que a vantagem dessa metodologia é a possibilidade de ser aplicada em qualquer análise distributiva, independentemente do número e do tipo de fatores determinantes considerados. Para Kolenikov e Shorrocks (2003), essa técnica apresenta as vantagens da decomposição ser sempre exata e dos fatores serem tratados de forma simétrica. 
Entretanto, de acordo com Müller (2008), o fato de não haver resíduo não é necessariamente um bom critério para identificar métodos ideais de decomposição. Isso porque, ao se utilizar aproximações integrais, é natural que exista um resíduo referente aos erros de aproximação.

\section{Aspectos metodológicos}

\subsection{Dados e variáveis}

Visando alcançar os objetivos propostos, são utilizadas informações anuais da PNAD referentes ao período de 1995 a 2009, com exceção do ano $2000 .^{5}$ A amostra analisada compreende os indivíduos residentes na zona urbana das nove regiões metropolitanas tratadas na pesquisa mais o Distrito Federal. A principal variável é a renda domiciliar per capita, deflacionada pelo método proposto por Corseuil e Foguel (2002). Dessa forma, essa renda é expressa em valores reais de setembro de 2012.

Valendo-se da renda domiciliar, calcula-se o índice de Gini, de modo a investigar a desigualdade de renda. Como neste trabalho a pobreza é analisada sob a ótica da insuficiência de renda, é necessário que se delimite uma linha que separe os indivíduos pobres dos não pobres. Portanto, optou-se pela linha de pobreza que leva em consideração a proposta de erradicação da pobreza por parte do governo federal. Nessa proposta, utiliza-se o valor de $\mathrm{R} \$ 140,00$ para diferenciar os pobres dos não pobres.

Dessa forma, para a mensuração da pobreza, aplica-se a família de índices FGT, instituída por Foster, Greer e Thorbecke (1984). Tais índices podem ser obtidos pela seguinte equação:

$$
P_{\alpha}(y ; z)=\frac{1}{n} \sum_{i=1}^{q}\left(\frac{z-y_{i}}{z}\right)^{\alpha}
$$

onde $n$ é o tamanho da população, $q$ é o número de pessoas abaixo da linha de pobreza, $z$ é a linha de pobreza, e $y_{i}$ é a renda per capita do i-ésimo indivíduo.

5 Nos anos em que se tem o Censo Demográfico, a PNAD não é realizada. 
Dessa equação, podem resultar três medidas de pobreza, $P_{0}, P_{1}$ e $P_{2}$. No caso em que $\alpha$ é igual a zero, obtém-se a medida de incidência de pobreza, ou seja, o percentual de pobres da economia em questão. Quando $\alpha$ é igual a 1, a medida obtida é a de insuficiência média de renda. Dessa forma, quanto maior esse valor, menor será a renda média dos pobres em relação à linha de pobreza. Essa medida indica a intensidade da pobreza. Já para o valor de $\alpha$ igual a dois, a medida reflete a severidade da pobreza. Segundo Barros et al. (2007), essa medida não apenas considera o número de pobres e a intensidade da pobreza, como também dá maior peso para os mais pobres, indicando assim uma desigualdade entre os indivíduos que vivem em condição de pobreza.

A família de índices FGT traz consigo uma propriedade desejável dos indicadores de pobreza, uma vez que são aditivamente decomponíveis. Em outras palavras, o índice de pobreza total é resultado da soma ponderada de cada medida de pobreza. Além disso, esse conjunto de índices satisfaz as propriedades básicas ${ }^{6}$ de um indicador de pobreza.

Segundo Araújo (2007), os resultados das decomposições são sensíveis à escolha do indicador de pobreza; assim, ao se utilizar a insuficiência média de renda $\left(P_{1}\right)$ ou a severidade da pobreza $\left(P_{2}\right)$ em vez da proporção de pobres $\left(P_{0}\right)$, o efeito desigualdade passa a ter maior parte na explicação da variação da pobreza analisada. Isso mostra que, na análise da intensidade da pobreza e da desigualdade de renda entre os pobres, o componente redistribuição passa a ter maior importância em relação à análise da proporção de pobres.

Neder e Silva (2004) atentam para o fato de que de esses índices podem ser analisados de acordo com o propósito das políticas públicas de combate à pobreza. Isso porque, ao se utilizar a proporção de pobres $\left(P_{0}\right)$, se atribui maior efetividade às políticas que elevam a renda dos menos pobres, ou seja, dos indivíduos cuja renda está mais próxima da linha de pobreza. Quando se analisa o hiato de pobreza $\left(P_{1}\right)$ e a severidade da pobreza $\left(P_{2}\right)$, têm-se informações a respeito daqueles indivíduos que estão muito abaixo da linha de pobreza, ou seja, os mais pobres dos pobres.

Dessa forma, como cada indicador mostra uma maneira de se identificar a população denominada pobre, a análise em conjunto desses indicadores apresenta resultados mais completos acerca do comportamento da pobreza.

6 Veja Sen (1976) para uma abordagem completa das propriedades axiomáticas dos indicadores de pobreza. 


\subsection{Decomposição de Shapley}

A análise dos determinantes da pobreza nas regiões metropolitanas do Brasil é aplicada tendo em vista a metodologia proposta por Shorrocks (1999). Tal metodologia é baseada no valor de Shapley, proveniente da teoria dos jogos cooperativos, e permite captar os desvios dos níveis de pobreza atribuídos a três fontes: renda média per capita, desigualdade e linha de pobreza.

A decomposição de Shapley é inspirada no clássico problema da teoria dos jogos cooperativos de divisão de um bolo adequadamente. A solução de Shapley atribui a cada jogador sua contribuição marginal média de todas as possíveis coalizões de agentes. Shorrocks (1999) reinterpreta tal fato, considerando os vários fatores que, em conjunto, determinam um indicador, como o nível geral de pobreza. Atribui-se a cada fator as contribuições marginais médias, de maneira que esses fatores podem ser "retirados" em sequência. Uma das características dessa técnica é que a decomposição é sempre exata, ou seja, não apresenta resíduo, e os fatores são tratados de forma simétrica. Dessa forma, um indicador de pobreza regional $(P)$ é completamente determinado através da seguinte identidade:

$$
P=P(L, \mu, z)
$$

onde $L$ representa a desigualdade de renda, obtida com o índice de Gini; $\mu$ é renda per capita, e $z$ mostra a linha de pobreza a ser adotada.

Assim, ao se fixar determinada linha de pobreza, o nível de pobreza ao longo do tempo $t(t=1,2)$ é estabelecido através da função $P=\left(\mu_{t}, L_{t}\right)$. A variação no índice de pobreza, $\Delta \mathrm{P}=\mathrm{P}_{2}-\mathrm{P}_{1}$, resultado de alterações no componente crescimento, $\mathrm{G}=\mu_{2} / \mu_{1}-1$, ou no componente redistribuiçãa, $R=L_{2}-L_{1}$.

A equação seguinte expressa a variação no índice de pobreza em termos de crescimento e redistribuição:

$$
\Delta P=P\left(\mu_{2}, L_{2},\right)-P\left(\mu_{1}, L_{1}\right)=P\left(\mu_{1}(1+G), L_{1}+R\right)-P\left(\mu_{t}, L_{t}\right)=F(G, R)
$$

A variação da pobreza por meio da decomposição de Shapley é explicada por meio da média das variações nos componentes crescimento e redistribuição. 
A equação a seguir (4) apresenta o efeito do componente crescimento, mostrando a variação da renda média. Nesta, a distribuição de renda se mantém inalterada.

$$
C_{G}^{S}=\frac{1}{2}\left[P\left(\mu_{2}, L_{1}\right)-P\left(\mu_{1}, L_{1}\right)\right]+\frac{1}{2}\left[P\left(\mu_{2}, L_{2}\right)-P\left(\mu_{1}, L_{2}\right)\right]
$$

onde $C_{G}^{S}$ é uma notação para efeito crescimento. O efeito redistribuição é representado por $C_{R}^{S}$, na equação seguinte (5). Verifica-se uma alteração nos níveis de distribuição de renda, ao passo que a renda média não se altera:

$$
C_{R}^{S}=\frac{1}{2}\left[P\left(\mu_{1}, L_{2}\right)-P\left(\mu_{1}, L_{1}\right)\right]+\frac{1}{2}\left[P\left(\mu_{2}, L_{2}\right)-P\left(\mu_{2}, L_{1}\right)\right]
$$

Dessa forma, a variação total do índice de pobreza é completamente explicada pela soma dos componentes crescimento e redistribuição, como mostra a equação abaixo (6):

$$
\Delta P=C_{G}^{S}+C_{R}^{S} 7
$$

\section{Resultados}

\subsection{Análise descritiva da pobreza}

A pobreza é analisada neste artigo sob a ótica unidimensional da privação de renda; para tanto, serão considerados os índices FGT $\left(P_{0}, P_{1}\right.$ e $\left.P_{2}\right)$, proporção de pobres, insuficiência média de renda e severidade da pobreza, respectivamente. A referência da linha de pobreza para esses índices é de $\mathrm{R} \$ 140,00$. Os períodos de análise são anuais e abrangem o período de 1995 a 2009. As unidades geográficas são compostas de nove regiões metropolitanas, mais o Distrito Federal.

Ao analisar a proporção de pobres (Figura 1), verificou-se elevação da pobreza entre 1995 e 2003 para quase todas as regiões metropolitanas analisadas, com exceção de Belém e do Rio de Janeiro, onde o ano de mais ele-

7 Os componentes crescimento $C_{G}^{S}$ e redistribuição $C_{R}^{S}$ serão tratados no resultados como EC e $\mathrm{ED}$, respectivamente. 
vada proporção de pobres foi 2001. A partir de 2004, os resultados indicam que a proporção de pobres foi sistematicamente reduzida.

Nesse período de redução, podem-se distinguir dois grupos de regiões metropolitanas. O grupo que teve uma redução de 3 a 6 pontos percentuais, formado pelas zonas metropolitanas do Sul e do Sudeste, mais o Distrito Federal; e o grupo em que a redução da proporção de pobres foi mais elevada, variando de 7 a 12 pontos percentuais.

A análise do indicador insuficiência média de renda (Figura 2) apresenta comportamento levemente diferente da proporção de pobres. Para esse indicador, o ano de mais elevada pobreza foi 2003 para apenas quatro regiões; as demais apresentam um ponto mais elevado de pobreza entre 1998 e 2001. Entretanto, a partir de 2004, o comportamento da insuficiência média de renda foi semelhante à proporção de pobres, com tendência de queda em todas as regiões metropolitanas durante o restante do período.

Ao analisar a severidade da pobreza (Figura 3), nota-se que houve melhora na desigualdade de renda entre os pobres na maioria das regiões, quando se compara o período inicial com o final.

No entanto, a análise anual mostra que esse indicador apresenta tendência de alta até 2003, para a grande maioria das regiões. Somente no Distrito Federal, a severidade da pobreza foi mais elevada no primeiro ano da análise. Essa tendência se altera a partir de 2004, verificando nesse período tendência de queda da severidade da pobreza para todas as regiões analisadas.

A atuação ao longo do tempo sugere que as regiões formam grupos com dinâmicas distintas entre 1995 e 2003. As regiões do Recife e de Porto Alegre apresentam aumento consistente tanto da proporção de pobres $\left(P_{0}\right)$, como também aumento no hiato da renda $\left(P_{1}\right)$ e agravamento da severidade da pobreza $\left(P_{2}\right)$ até 2003 . Em Belém, também há alta nos três indicadores, porém até 2001. Já no Rio de Janeiro, em São Paulo, em Curitiba e em Fortaleza, a severidade da pobreza começa a declinar a partir de 2001.

O Distrito Federal difere das demais, uma vez que, apesar de ter apresentado aumento na proporção de pobres até 2003, a intensidade da pobreza diminui a partir de 1999, e a severidade da pobreza apresenta tendência de queda desde o primeiro ano da análise. A partir de 2004, o que se verifica é a diminuição de todos os indicadores de pobreza. É importante observar que as variações em incidência, intensidade e desigualdade da pobreza são distintas. 
Figura 1 Variação da proporção de pobres de 1995 a 2009

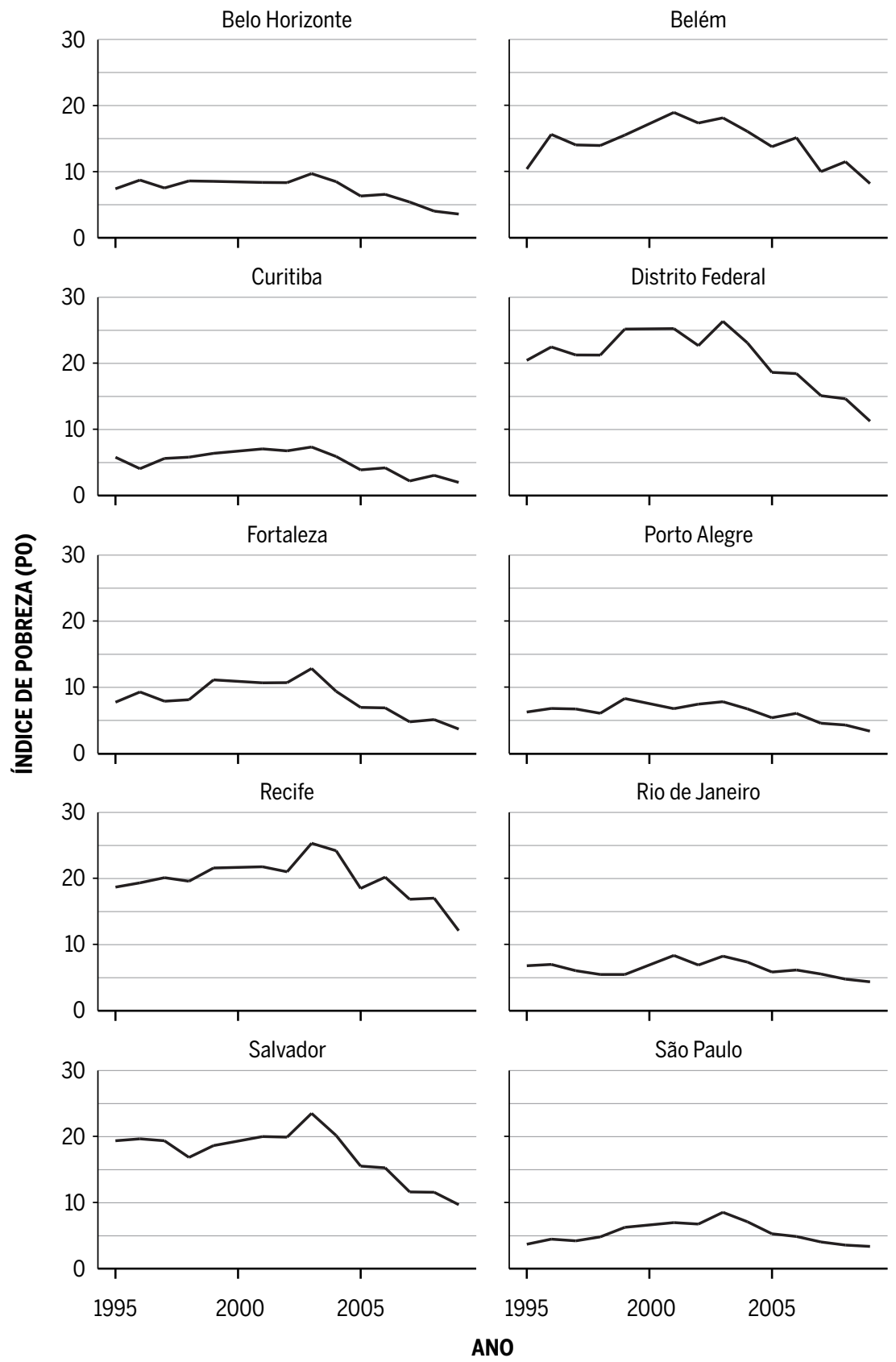

Fonte: Elaborada pelos autores com base nas PNADs/IBGE. 
Figura 2 Variação da insuficiência média de renda entre 1995 e 2009

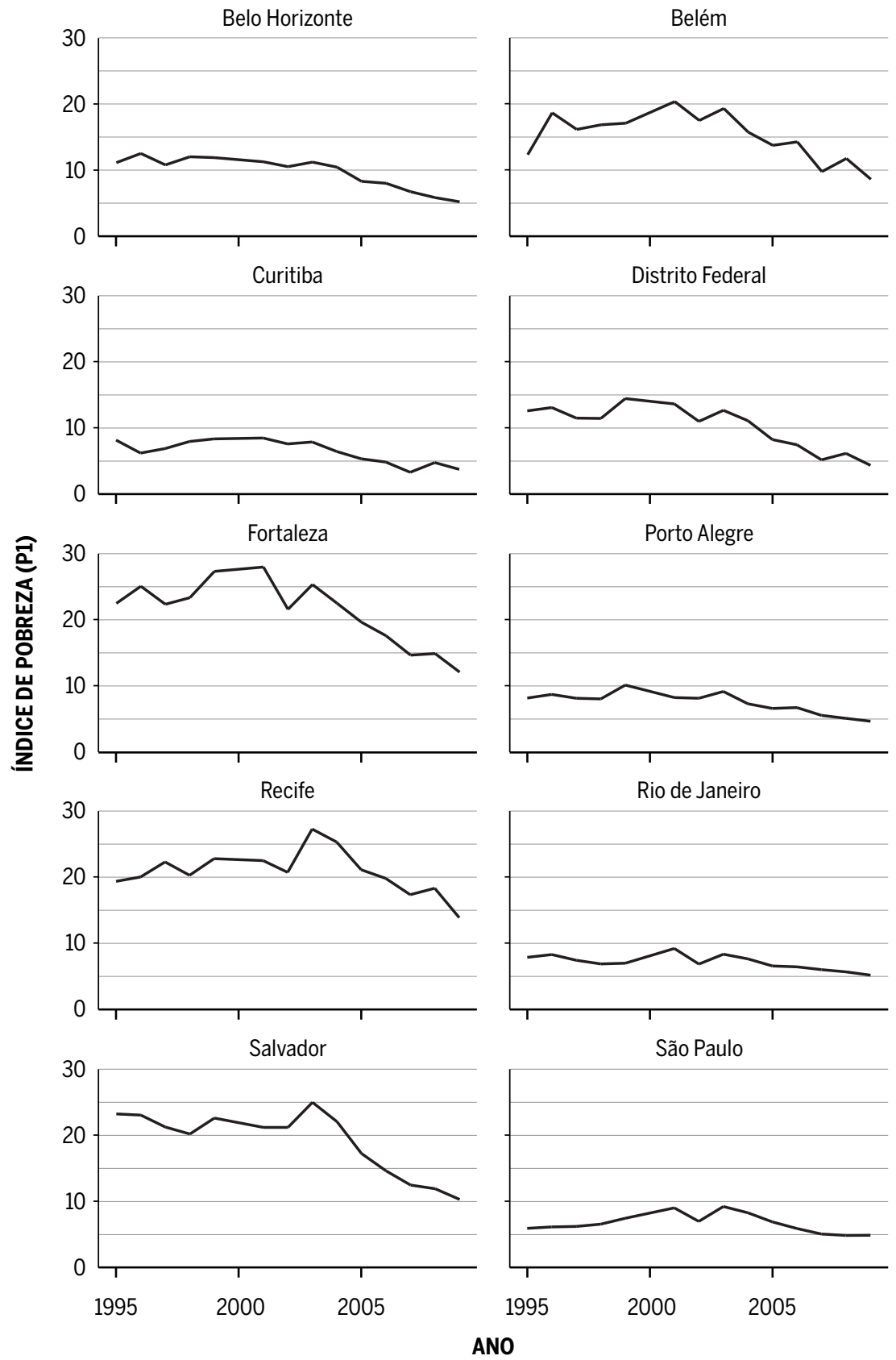

Fonte: Elaborada pelos autores com base nas PNADs/IBGE. 
Figura 3 Variação da severidade da pobreza entre 1995 e 2009
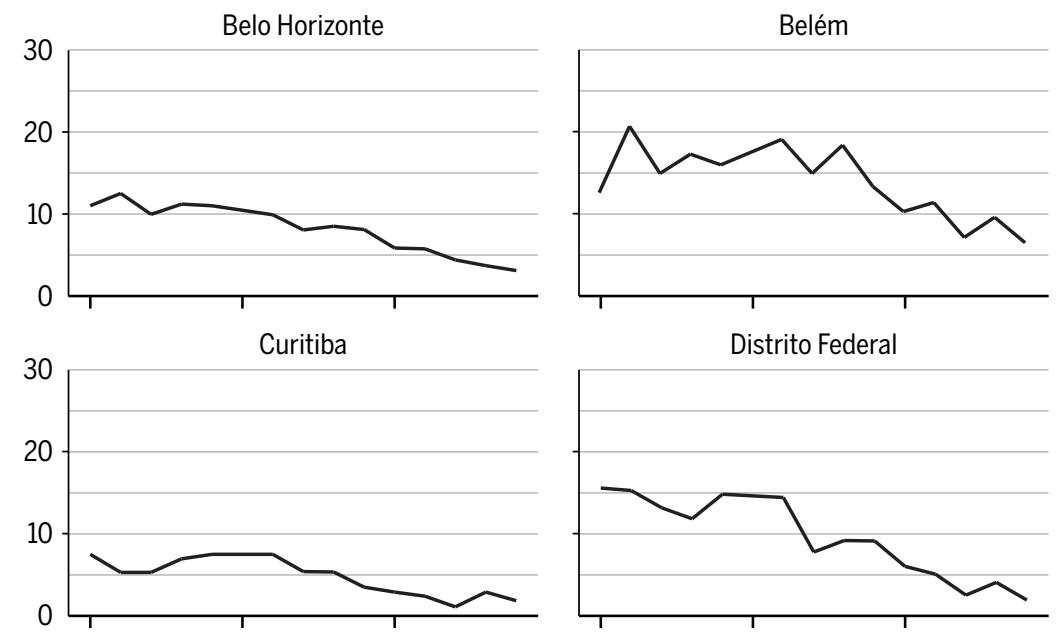

Distrito Federal
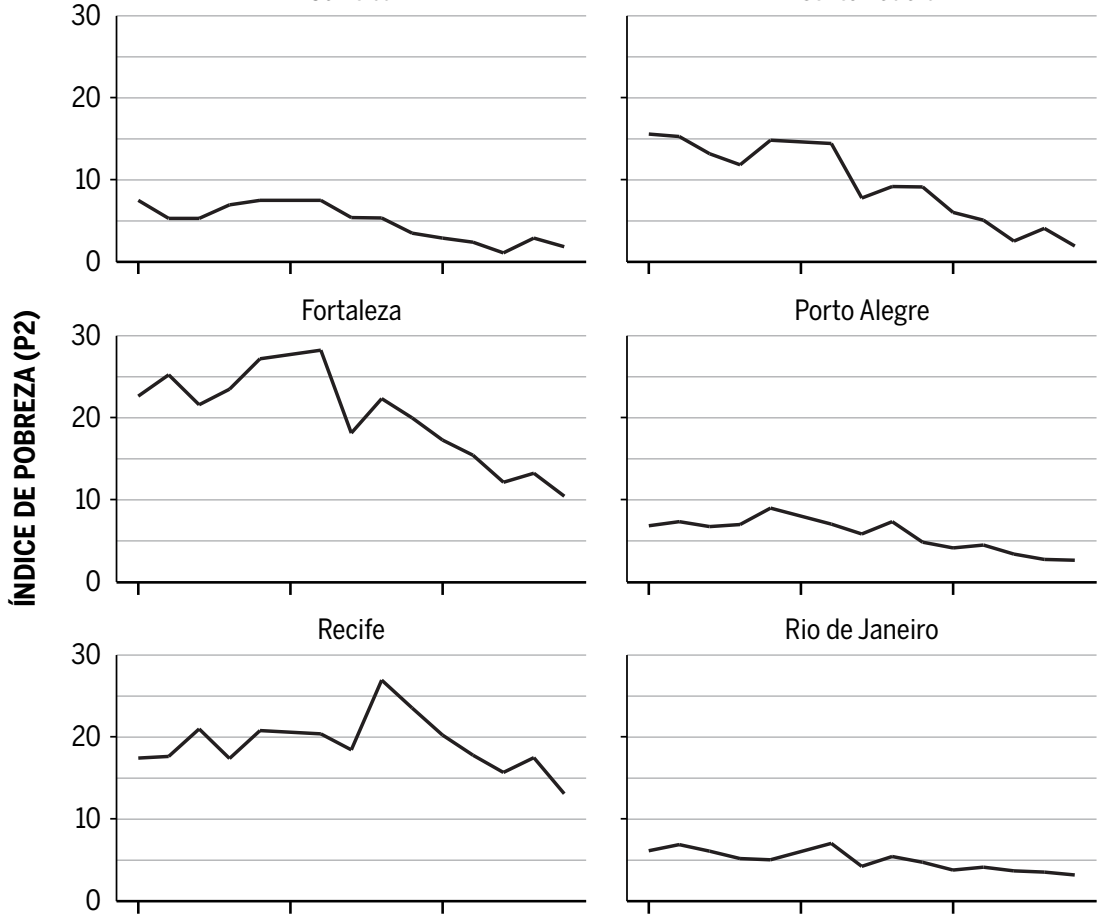

Rio de Janeiro
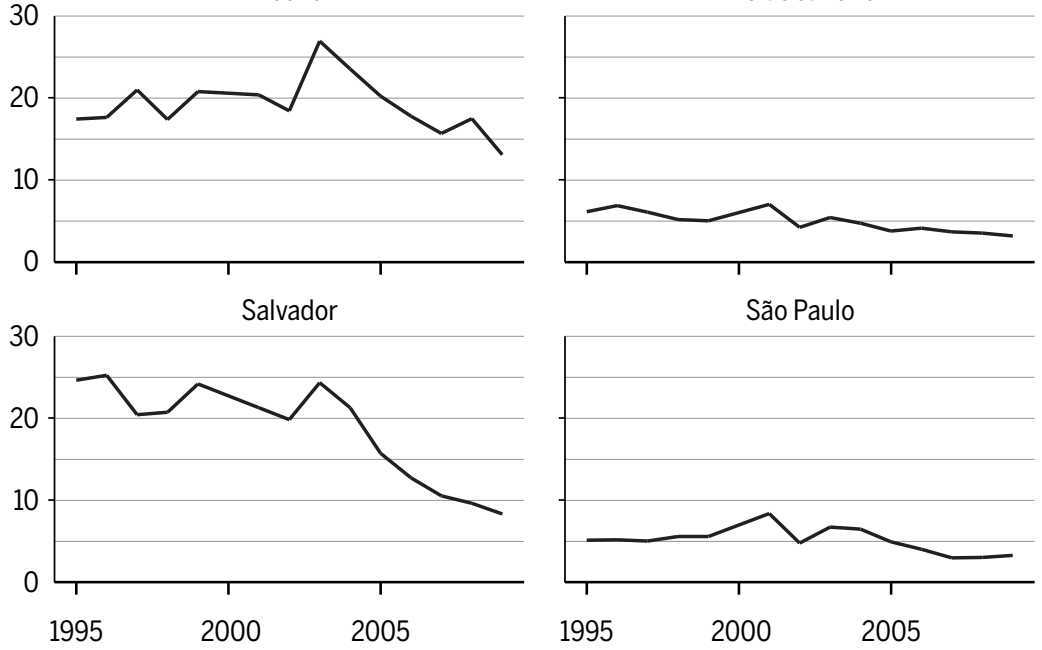

ANO

Fonte: Elaborada pelos autores com base nas PNADs/IBGE. 
De maneira geral, observam-se dois períodos distintos de comportamento dos níveis de pobreza, especialmente em relação à proporção de pobres. Até 2003, verifica-se tendência de alta, enquanto, a partir de 2004, essa tendência se inverte, alcançando o ponto mais baixo de pobreza no ano de 2009.

Esse comportamento distinto entre períodos também se verifica no índice de insuficiência média de renda $\left(P_{1}\right)$ em todas as regiões. A partir de 2004, há uma queda da pobreza em quase todos os períodos, ao passo que até 2003 prevalece períodos de alta para a maioria das regiões metropolitanas. Entretanto, a elevação desse indicador até 2003 é inferior à verificada na proporção de pobres na grande maioria das regiões metropolitanas, e em algumas permaneceu praticamente estável.

Fato semelhante ocorre com o indicador de severidade da pobreza $\left(P_{2}\right)$. Para esse índice, os períodos só não se mostram distintos para o Distrito Federal.

\subsection{Análise descritiva da desigualdade e do rendimento médio}

A análise da desigualdade de renda (Tabela 1), calculada através do índice de Gini, apresenta queda em todas as regiões, com exceção do Distrito Federal, para o período entre 1995 e 2009.

Tabela 1 Índice de Gini entre 1995 e 2009

\begin{tabular}{|c|c|c|c|c|c|c|c|c|c|c|c|c|c|c|}
\hline \multirow{2}{*}{$\begin{array}{l}\text { Região } \\
\text { Metropolitana }\end{array}$} & \multicolumn{14}{|c|}{ RENDA MÉDIA DOMICILIAR PER CAPITA } \\
\hline & 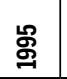 & ஜ & ஓ् & $\stackrel{\text { ஜ }}{\stackrel{2}{9}}$ & 呑 & ్ㅗ․ & శ్రి & రి & ఫัర & 옹 & రి & ర్సి & రి & 올 \\
\hline Belém & 0,57 & 0,596 & 0,57 & 0,578 & 0,565 & 0,574 & 0,567 & 0,537 & 0,54 & 0,537 & 0,535 & 0,524 & 0,521 & 0,506 \\
\hline Fortaleza & 0,59 & 0,605 & 0,592 & 0,593 & 0,613 & 0,621 & 0,593 & 0,57 & 0,59 & 0,571 & 0,552 & 0,541 & 0,548 & 0,547 \\
\hline Recife & 0,569 & 0,589 & 0,582 & 0,596 & 0,6 & 0,605 & 0,601 & 0,58 & 0,607 & 0,59 & 0,589 & 0,564 & 0,581 & 0,56 \\
\hline Salvador & 0,621 & 0,618 & 0,627 & 0,596 & 0,608 & 0,604 & 0,613 & 0,59 & 0,572 & 0,571 & 0,564 & 0,568 & 0,567 & 0,563 \\
\hline Belo Horizonte & 0,579 & 0,571 & 0,562 & 0,568 & 0,564 & 0,547 & 0,553 & 0,556 & 0,548 & 0,546 & 0,549 & 0,532 & 0,52 & 0,517 \\
\hline Rio de Janeiro & 0,561 & 0,571 & 0,561 & 0,559 & 0,538 & 0,553 & 0,545 & 0,554 & 0,54 & 0,55 & 0,546 & 0,542 & 0,542 & 0,534 \\
\hline São Paulo & 0,528 & 0,526 & 0,531 & 0,552 & 0,544 & 0,546 & 0,544 & 0,54 & 0,521 & 0,54 & 0,527 & 0,512 & 0,496 & 0,5 \\
\hline Curitiba & 0,552 & 0,542 & 0,547 & 0,547 & 0,55 & 0,549 & 0,513 & 0,518 & 0,526 & 0,516 & 0,508 & 0,502 & 0,492 & 0,481 \\
\hline Porto Alegre & 0,569 & 0,558 & 0,543 & 0,556 & 0,562 & 0,552 & 0,554 & 0,537 & 0,525 & 0,525 & 0,537 & 0,505 & 0,518 & 0,5 \\
\hline Distrito Federal & 0,574 & 0,577 & 0,584 & 0,601 & 0,613 & 0,608 & 0,609 & 0,614 & 0,605 & 0,578 & 0,595 & 0,596 & 0,594 & 0,59 \\
\hline
\end{tabular}

Fonte: Elaborada pelos autores com base nas PNADs/IBGE. 
Quando se analisa cada período separadamente, nota-se que até 2004 ocorre tendência de queda no índice de Gini da maioria das regiões analisadas, sendo essa tendência menos acentuada do que a do período seguinte. No período posterior a 2004, a tendência é mais acentuada e ocorre em todas as regiões analisadas.

Ao se examinar a desigualdade de renda de cada região metropolitana, observou-se que o ano com mais elevado índice de Gini foi 2001. Assim, de 1995 a 2001, a tendência verificada foi de aumento na desigualdade de renda. A partir desse ano e até 2009 , houve tendência de queda na desigualdade.

A renda média domiciliar per capita (Tabela 2) apresentou tendência de queda em todas as regiões metropolitanas até 2003. No período seguinte, a partir de 2004, verifica-se substancial aumento no rendimento médio de todas as regiões; no Distrito Federal, por exemplo, o crescimento na renda foi da ordem de $32 \%$.

Tabela 2 Renda média domiciliar per capita entre 1995 e 2009

\begin{tabular}{|c|c|c|c|c|c|c|c|c|c|c|c|c|c|c|}
\hline \multirow{2}{*}{$\begin{array}{l}\text { Região } \\
\text { Metropolitana }\end{array}$} & \multicolumn{14}{|c|}{ RENDA MÉDIA DOMICILIAR PER CAPITA } \\
\hline & 뇽 & \& & ફ & \& & gㅇ & 옹 & ర్ ญ & ర్ & ষ্ণ & 옹 & ర్ & 옹 & ర్ ర్ & 유 \\
\hline Belém & 832,43 & 829,72 & 802,20 & 837,76 & 736,17 & 633,26 & 662,11 & 566,66 & 610,59 & 650,97 & 564,77 & 743,70 & 646,82 & 727,78 \\
\hline Fortaleza & 602,15 & 605,80 & 611,02 & 598,12 & 571,53 & 623,66 & 587,90 & 502,62 & 567,73 & 586,80 & 537,83 & 617,54 & 612,30 & 730,05 \\
\hline Recife & 590,93 & 640,76 & 611,12 & 657,01 & 619,85 & 654,36 & 648,82 & 525,33 & 598,60 & 631,08 & 589,02 & 628,74 & 640,24 & 735,17 \\
\hline Salvador & 690,20 & 725,32 & 774,51 & 741,87 & 704,37 & 680,01 & 708,29 & 580,78 & 611,41 & 667,92 & 665,08 & 772,66 & 769,10 & 864,78 \\
\hline Belo Horizonte & 881,13 & 868,21 & 925,69 & 874,32 & 819,58 & 789,68 & 820,30 & 746,07 & 785,51 & 841,71 & 878,16 & 934,51 & 927,96 & 1059,63 \\
\hline Rio de Janeiro & 1005,97 & 1074,67 & 1007,23 & 1051,20 & 971,05 & 963,18 & 942,56 & 914,76 & 937,80 & 965,02 & 986,43 & 1019,24 & 1041,30 & 1102,07 \\
\hline São Paulo & 1176,95 & 1164,54 & 1181,32 & 1216,20 & 1051,06 & 1070,86 & 1060,43 & 955,04 & 908,78 & 1041,85 & 1013,19 & 1090,52 & 1034,35 & 1082,95 \\
\hline Curitiba & 1105,021 & 1090,48 & 1089,81 & 1073,28 & 977,27 & 1015,90 & 981,12 & 860,42 & 990,29 & 1029,32 & 950,67 & 1211,56 & 1150,20 & 1213,70 \\
\hline Porto Alegre & 1065,56 & 1077,80 & 1045,90 & 1076,68 & 1016,82 & 1040,72 & 995,34 & 948,77 & 980,52 & 1036,18 & 1017,24 & 1038,83 & 1062,49 & 1102,19 \\
\hline Distrito Federal & 1264,34 & 1251,19 & 1366,80 & 1429,37 & 1241,66 & 1249.31 & 1335.92 & 1234.39 & 1254,76 & 1331,75 & 139420 & 1676.52 & 15323 & \\
\hline
\end{tabular}

Fonte: Elaborada pelos autores com base nas PNADs/IBGE.

Em razão das diferenças entre os períodos analisados, em relação à variação dos indicadores de pobreza, utiliza-se o teste de Chow e as regressões recursivas para mostrar a significância dessa diferença.

Os resultados do teste de Chow indicam que as diferenças mais significativas nos parâmetros de pobreza estão em 2003 e 2004, já que esses 
apresentam os menores $p$-valores, 0,003 e 0,0029, respectivamente. Os resultados das regressões recursivas apontam que há reversão de tendência a partir de 2003. Mais informações a respeito dos testes encontram-se no Apêndice deste trabalho.

As diferenças entre os períodos analisados atentam para a importância de decompor a variação da pobreza em seus dois macrodeterminantes imediatos, crescimento e redistribuição. Dessa forma, podem-se obter respostas a respeito de qual fator foi mais importante para explicar essa diferença de comportamento da pobreza encontrada entre os períodos.

\subsection{Decomposição temporal da pobreza}

A variação da pobreza verificada via decomposição de Shapley é explicada através da média das variações nos componentes crescimento e redistribuição. O efeito do componente crescimento ( $E C)$ mostra a variação da renda média quando a distribuição de renda se mantém inalterada. $O$ efeito redistribuição é representado por $E D$ e é verificado por meio de uma alteração nos níveis de distribuição de renda, enquanto a renda média não se altera.

Para efeitos de análise, quando o componente crescimento apresentar sinal negativo, significa que o aumento da renda dos mais pobres contribuiu para a redução da pobreza; já o sinal positivo desse componente aponta que a queda no rendimento médio resultou em elevação da pobreza. Da mesma forma, o sinal negativo do componente redistribuição indica que a queda na desigualdade de renda resultou em queda na pobreza, ocorrendo o inverso para o sinal positivo desse componente.

Os resultados da decomposição da variação da pobreza para todo o período da amostra mostram que, para metade das regiões metropolitanas, o componente redistribuição é mais importante para explicar o comportamento da proporção de pobres. Por outro lado, na outra metade, é o componente crescimento que mais explica as variações da pobreza (Tabela 3).

Mais especificamente, nas regiões metropolitanas de Belém, Recife, Salvador, Belo Horizonte e Distrito Federal, o componente crescimento é o principal determinante das variações nos níveis de pobreza, enquanto em Fortaleza, no Rio de Janeiro, em São Paulo, em Curitiba e em Porto Alegre é o componente redistribuição que tem maior influência no comportamento da proporção de pobres. 
Tabela 3 Decomposição da variação da pobreza (P0) nas regiões metropolitanas

\begin{tabular}{|c|c|c|c|c|c|c|c|c|c|c|c|c|c|c|}
\hline \multirow[b]{2}{*}{$\begin{array}{l}\text { Região } \\
\text { Metropoli- } \\
\text { tana }\end{array}$} & \multirow[b]{2}{*}{ 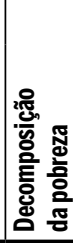 } & \multicolumn{13}{|c|}{ PROPORÇÃO DE POBRES (P0) } \\
\hline & & $\begin{array}{l}\mathscr{2} \\
\text { ஓ } \\
\text { 岁 } \\
\text { \% }\end{array}$ & 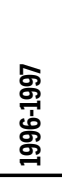 & $\begin{array}{l}\stackrel{\circ}{\circ} \\
\stackrel{乛}{\circ}\end{array}$ & $\begin{array}{l}\text { \% } \\
\text { \% } \\
\text { 。영 }\end{array}$ & 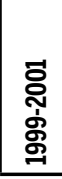 & 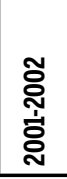 & 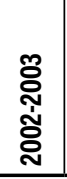 & 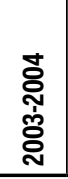 & 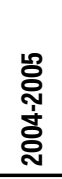 & 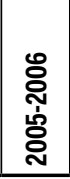 & 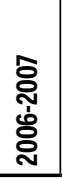 & 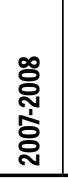 & 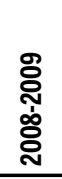 \\
\hline \multirow{3}{*}{ Belém } & $\Delta \mathrm{P}$ & 5.24 & -1.58 & -0.10 & 1.58 & 3.42 & -1.59 & 0.78 & -2.05 & -2.31 & 1.38 & -5.14 & 1.50 & -3.29 \\
\hline & EC & 0.05 & 0.44 & -0.74 & 2.50 & 4.91 & -0.99 & 4.56 & -2.12 & -2.21 & 4.73 & -6.51 & 3.11 & -2.64 \\
\hline & ED & 5.19 & -2.02 & 0.66 & -0.92 & -1.49 & -0.60 & -3.78 & 0.07 & -0.10 & -3.35 & 1.36 & -1.61 & -0.65 \\
\hline \multirow{3}{*}{ Fortaleza } & $\Delta P$ & 2.03 & -1.22 & -0.01 & 3.93 & 0.06 & -2.56 & 3.68 & -3.27 & -4.47 & -0.18 & -3.35 & -0.46 & -3.39 \\
\hline & $\mathrm{EC}$ & -0.00 & -0.15 & 0.65 & 1.27 & -2.39 & 1.95 & 5.72 & -5.13 & -2.05 & 3.46 & -4.03 & 0.15 & -4.79 \\
\hline & ED & 2.03 & -1.07 & -0.66 & 2.66 & 2.47 & -4.51 & -2.04 & 1.86 & -2.42 & -3.64 & 0.68 & -0.61 & 1.40 \\
\hline \multirow{3}{*}{ Recife } & $\Delta P$ & 0.65 & 0.78 & -0.54 & 2.00 & 0.19 & -0.77 & 4.31 & -1.13 & -5.69 & 1.71 & -3.35 & 0.17 & -4.93 \\
\hline & $\mathrm{EC}$ & -2.47 & 1.14 & -1.90 & 1.26 & -1.31 & 0.64 & 6.58 & -5.18 & -2.79 & 3.47 & -1.89 & -0.52 & -3.85 \\
\hline & ED & 3.13 & -0.36 & 1.36 & 0.74 & 1.50 & -1.41 & -2.27 & 4.05 & -2.90 & -1.76 & -1.46 & 0.69 & -1.08 \\
\hline \multirow{3}{*}{ Salvador } & $\Delta \mathrm{P}$ & 0.28 & -0.28 & -2.52 & 1.79 & 1.35 & -0.08 & 3.60 & -3.34 & -4.64 & -0.27 & -3.63 & -0.05 & -1.89 \\
\hline & EC & -0.99 & -1.90 & 0.77 & 0.97 & 1.12 & -1.13 & 6.01 & -1.43 & -3.50 & -0.00 & -4.22 & 0.08 & -2.14 \\
\hline & ED & 1.27 & 1.62 & -3.29 & 0.82 & 0.23 & 1.05 & -2.41 & -1.90 & -1.14 & -0.27 & 0.59 & -0.13 & 0.25 \\
\hline \multirow{3}{*}{$\begin{array}{l}\text { Belo } \\
\text { Horizonte }\end{array}$} & $\Delta P$ & 1.59 & -1.44 & 1.27 & -0.07 & -0.20 & -0.04 & 1.65 & -1.46 & -2.61 & 0.30 & -1.38 & -1.66 & -0.53 \\
\hline & EC & 0.13 & -1.00 & 0.68 & 1.03 & 0.85 & -0.68 & 2.24 & -1.06 & -1.65 & -0.46 & -0.93 & 0.04 & -1.36 \\
\hline & ED & 1.46 & -0.44 & 0.59 & -1.10 & -1.05 & 0.64 & -0.59 & -0.40 & -0.95 & 0.76 & -0.45 & -1.70 & 0.83 \\
\hline \multirow{3}{*}{$\begin{array}{l}\text { Rio de } \\
\text { Janeiro }\end{array}$} & $\Delta P$ & 0.20 & -0.95 & -0.57 & -0.00 & 2.88 & -1.45 & 1.34 & -0.90 & -1.50 & 0.31 & -0.61 & -0.77 & -0.40 \\
\hline & $\mathrm{EC}$ & -0.64 & 0.39 & -0.43 & 0.68 & 0.31 & 0.40 & 0.26 & -0.35 & -1.05 & -0.03 & -0.63 & -0.17 & -0.55 \\
\hline & ED & 0.84 & -1.34 & -0.14 & -0.68 & 2.57 & -1.85 & 1.08 & -0.55 & -0.44 & 0.34 & 0.02 & -0.60 & 0.15 \\
\hline \multirow{3}{*}{$\begin{array}{l}\text { São } \\
\text { Paulo }\end{array}$} & $\Delta \mathrm{P}$ & 0.77 & -0.26 & 0.61 & 1.45 & 0.71 & -0.22 & 1.78 & -1.43 & -1.82 & -0.41 & -0.83 & -0.47 & -0.20 \\
\hline & EC & 0.12 & -0.17 & -0.16 & 1.21 & -0.08 & 0.35 & 1.65 & 0.46 & -1.96 & 1.12 & -0.65 & 0.24 & -0.29 \\
\hline & $E D$ & 0.65 & -0.09 & 0.77 & 0.24 & 0.79 & -0.57 & 0.13 & -1.89 & 0.14 & -1.53 & -0.18 & -0.71 & 0.09 \\
\hline \multirow{3}{*}{ Curitiba } & $\Delta \mathrm{P}$ & -1.73 & 1.55 & 0.19 & 0.58 & 0.67 & -0.29 & 0.57 & -1.44 & -2.02 & 0.31 & -1.99 & 0.86 & -1.07 \\
\hline & EC & 0.09 & -0.00 & -0.00 & 1.07 & -0.30 & 0.52 & 1.56 & -1.77 & -1.05 & 1.54 & -2.05 & 0.20 & -0.38 \\
\hline & ED & -1.82 & 1.55 & 0.19 & -0.48 & 0.97 & -0.80 & -0.99 & 0.34 & -0.97 & -1.24 & 0.06 & 0.66 & -0.69 \\
\hline \multirow{3}{*}{$\begin{array}{l}\text { Porto } \\
\text { Alegre }\end{array}$} & $\Delta P$ & 0.53 & -0.07 & -0.65 & 2.23 & -1.53 & 0.67 & 0.37 & -1.08 & -1.34 & 0.66 & -1.50 & -0.27 & -0.92 \\
\hline & EC & -0.04 & 0.33 & -0.36 & 0.57 & -0.14 & 0.73 & 0.43 & -0.37 & -1.14 & 0.47 & -0.48 & -0.08 & -0.28 \\
\hline & ED & 0.57 & -0.40 & -0.29 & 1.67 & -1.39 & -0.06 & -0.06 & -0.70 & -0.21 & 0.19 & -1.02 & -0.19 & -0.64 \\
\hline \multirow{3}{*}{$\begin{array}{l}\text { Distrito } \\
\text { Federal }\end{array}$} & $\Delta P$ & 1.55 & -1.40 & 0.23 & 3.00 & -0.45 & 0.03 & 2.13 & -3.45 & -2.42 & -0.08 & -2.11 & 0.34 & -1.43 \\
\hline & EC & 0.23 & -1.15 & -0.37 & 1.64 & 0.00 & -1.21 & 1.28 & -0.31 & -1.19 & -0.33 & -2.69 & 0.97 & -1.25 \\
\hline & ED & 1.32 & -0.25 & 0.60 & 1.36 & -0.45 & 124 & 085 & $-3 \cdot 14$ & -1.24 & 0.25 & 0.59 & -0.63 & -0.18 \\
\hline
\end{tabular}

Fonte: Elaborada pelos autores com base nas PNADs/IBGE. 
Tabela 4 Decomposição da variação da pobreza (P1) nas regiões metropolitanas

\begin{tabular}{|c|c|c|c|c|c|c|c|c|c|c|c|c|c|c|}
\hline \multirow[b]{2}{*}{$\begin{array}{l}\text { Região } \\
\text { Metropoli- } \\
\text { tana }\end{array}$} & \multirow[b]{2}{*}{ 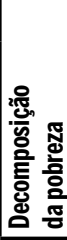 } & \multicolumn{13}{|c|}{ INSUFICIÊNCIA MÉDIA DE RENDA (P1) } \\
\hline & & 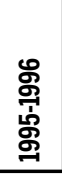 & 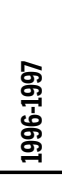 & 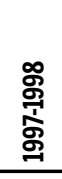 & $\begin{array}{l}\text { \% } \\
\text { \% } \\
\text { \% } \\
\text { \% }\end{array}$ & 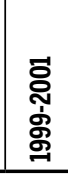 & 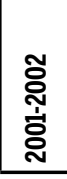 & 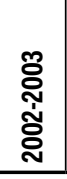 & 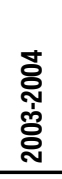 & 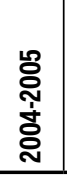 & $\begin{array}{l}\text { ठั. } \\
\text { पे } \\
\text { ஸे }\end{array}$ & 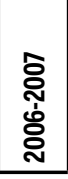 & $\begin{array}{l}\text { o } \\
\text { స్ } \\
\text { స్రి }\end{array}$ & 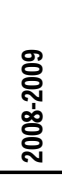 \\
\hline \multirow{3}{*}{ Belém } & $\Delta P$ & 2.43 & -0.96 & 0.27 & 0.10 & 1.24 & -1.09 & 0.69 & -1.37 & -0.76 & 0.21 & -1.72 & 0.76 & -1.20 \\
\hline & EC & 0.03 & 0.30 & -0.37 & 1.20 & 1.64 & -0.51 & 1.74 & -0.81 & -0.68 & 1.44 & -2.27 & 1.00 & -0.82 \\
\hline & ED & 2.40 & -1.26 & 0.64 & -1.10 & -0.40 & -0.58 & -1.05 & -0.56 & -0.08 & -1.23 & 0.55 & -0.24 & -0.38 \\
\hline \multirow{3}{*}{ Fortaleza } & $\Delta \mathrm{P}$ & 0.99 & -1.04 & 0.38 & 1.52 & 0.25 & -2.44 & 1.42 & -1.07 & -1.10 & -0.78 & -1.11 & 0.09 & -1.07 \\
\hline & EC & -0.08 & -0.12 & 0.29 & 0.65 & -1.35 & 0.88 & 2.48 & -1.95 & -0.45 & 1.09 & -1.50 & 0.08 & -1.46 \\
\hline & ED & 1.07 & -0.92 & 0.09 & 0.87 & 1.60 & -3.32 & -1.06 & 0.88 & -0.65 & -1.87 & 0.39 & 0.01 & 0.39 \\
\hline \multirow{3}{*}{ Recife } & $\Delta \mathrm{P}$ & 0.25 & 0.87 & -0.77 & 0.96 & -0.11 & -0.68 & 2.50 & -0.75 & -1.59 & -0.50 & -0.96 & 0.37 & -1.70 \\
\hline & EC & -0.99 & 0.58 & -0.90 & 0.77 & -0.75 & 0.12 & 3.00 & -2.01 & -0.75 & 0.88 & -0.77 & -0.20 & -1.25 \\
\hline & ED & 1.24 & 0.29 & 0.13 & 0.21 & 0.64 & -0.80 & -0.50 & 1.26 & -0.84 & -1.38 & -0.19 & 0.57 & -0.45 \\
\hline \multirow{3}{*}{ Salvador } & $\Delta P$ & -0.08 & -0.69 & -0.40 & 0.92 & -0.54 & -0.00 & 1.45 & -1.12 & -1.83 & -1.00 & -0.82 & -0.21 & -0.62 \\
\hline & EC & -0.57 & -0.76 & 0.48 & 0.54 & 0.41 & -0.50 & 2.57 & -0.69 & -1.03 & 0.05 & -1.27 & 0.03 & -0.82 \\
\hline & ED & 0.49 & 0.08 & -0.88 & 0.38 & -0.95 & 0.50 & -1.12 & -0.43 & -0.81 & -1.05 & 0.45 & -0.24 & 0.20 \\
\hline \multirow{3}{*}{$\begin{array}{l}\text { Belo } \\
\text { Horizonte }\end{array}$} & $\Delta P$ & 0.53 & -0.65 & 0.47 & -0.05 & -0.24 & -0.29 & 0.26 & -0.29 & -0.82 & -0.10 & -0.49 & -0.34 & -0.24 \\
\hline & EC & 0.09 & -0.38 & 0.34 & 0.42 & 0.24 & -0.25 & 0.69 & -0.38 & -0.45 & -0.22 & -0.30 & 0.03 & -0.41 \\
\hline & ED & 0.44 & -0.27 & 0.13 & -0.47 & -0.48 & -0.04 & -0.43 & 0.09 & -0.37 & 0.12 & -0.19 & -0.37 & 0.17 \\
\hline \multirow{3}{*}{$\begin{array}{l}\text { Rio de } \\
\text { Janeiro }\end{array}$} & $\Delta \mathrm{P}$ & 0.16 & -0.33 & -0.21 & 0.04 & 0.85 & -0.90 & 0.57 & -0.27 & -0.41 & -0.05 & -0.16 & -0.13 & -0.19 \\
\hline & $\mathrm{EC}$ & -0.30 & 0.27 & -0.16 & 0.29 & 0.04 & 0.11 & 0.16 & -0.13 & -0.14 & -0.09 & -0.13 & -0.08 & -0.19 \\
\hline & ED & 0.46 & -0.60 & -0.05 & -0.25 & 0.81 & -1.01 & 0.41 & -0.14 & -0.27 & 0.04 & -0.03 & -0.05 & -0.00 \\
\hline \multirow{3}{*}{$\begin{array}{l}\text { São } \\
\text { Paulo }\end{array}$} & $\Delta P$ & 0.08 & 0.03 & 0.13 & 0.34 & 0.60 & -0.78 & 0.85 & -0.36 & -0.53 & -0.37 & -0.32 & -0.08 & 0.01 \\
\hline & EC & 0.02 & -0.04 & -0.08 & 0.53 & -0.08 & 0.04 & 0.55 & 0.27 & -0.59 & 0.09 & -0.20 & 0.14 & -0.11 \\
\hline & ED & 0.06 & 0.07 & 0.21 & -0.19 & 0.68 & -0.82 & 0.30 & -0.61 & 0.06 & -0.46 & -0.12 & -0.22 & 0.10 \\
\hline \multirow{3}{*}{ Curitiba } & $\Delta \mathrm{P}$ & -0.75 & 0.25 & 0.42 & 0.15 & 0.05 & -0.34 & 0.11 & -0.55 & -0.43 & -0.19 & -0.59 & 0.56 & -0.39 \\
\hline & $\mathrm{EC}$ & 0.04 & 0.00 & 0.06 & 0.37 & -0.17 & 0.15 & 0.60 & -0.63 & -0.15 & 0.27 & -0.53 & 0.10 & -0.10 \\
\hline & $E D$ & -0.79 & 0.25 & 0.36 & -0.22 & 0.22 & -0.49 & -0.49 & 0.08 & -0.28 & -0.44 & -0.06 & 0.46 & -0.29 \\
\hline \multirow{3}{*}{$\begin{array}{l}\text { Porto } \\
\text { Alegre }\end{array}$} & $\Delta \mathrm{P}$ & 0.22 & -0.23 & -0.03 & 0.80 & -0.72 & -0.04 & 0.39 & -0.71 & -0.28 & 0.05 & -0.45 & -0.17 & -0.17 \\
\hline & EC & -0.05 & 0.13 & -0.12 & 0.26 & -0.11 & 0.20 & 0.24 & -0.16 & -0.25 & 0.07 & -0.07 & -0.08 & -0.10 \\
\hline & ED & 0.27 & -0.36 & 0.09 & 0.54 & -0.61 & -0.24 & 0.15 & -0.55 & -0.03 & -0.02 & -0.38 & -0.09 & -0.07 \\
\hline \multirow{3}{*}{$\begin{array}{l}\text { Distrito } \\
\text { Federal }\end{array}$} & $\Delta P$ & 0.19 & -0.61 & -0.02 & 1.15 & -0.31 & -1.02 & 0.64 & -0.59 & -1.10 & -0.30 & -0.87 & 0.37 & -0.69 \\
\hline & $\mathrm{EC}$ & 0.05 & -0.39 & -0.20 & 0.78 & -0.04 & -0.45 & 0.64 & -0.12 & -0.34 & -0.21 & -0.72 & 0.32 & -0.30 \\
\hline & ED & 0.14 & -0.22 & 0.18 & 0.37 & -0.27 & -0.57 & 0.00 & -0.47 & -0.76 & -0.09 & -0.15 & 0.05 & -0.39 \\
\hline
\end{tabular}

Fonte: Elaborada pelos autores com base nas PNADs/IBGE. 
Os resultados também indicam que, até o período 2001-2002, o componente desigualdade de renda é predominante na maioria das regiões analisadas. A partir do período 2002-2003, o componente que mais explica a variação nos níveis de pobreza é o crescimento da renda.

Pelos resultados até aqui analisados, percebe-se que, em período de baixo crescimento, a renda ficou concentrada, e a pobreza aumentou. Quando começa a ocorrer crescimento, a renda per capita aumenta, intensificando mais que a distribuição e gerando diminuição da pobreza.

$\mathrm{Na}$ decomposição dos indicadores de insuficiência média de renda ( $\mathrm{Ta}$ bela 4), observou-se composição dos determinantes semelhante à proporção de pobres.

Em outras palavras, os fatores crescimento e distribuição são igualmente importantes na explicação da variação da pobreza. Isso porque em cinco regiões o crescimento explica mais essa variação, e nas outras cinco regiões a desigualdade é o determinante mais importante da pobreza.

Para o indicador de severidade da pobreza (Tabela 5), o exercício de decomposição aponta o componente redistribuição como o principal determinante da variação da pobreza no período 1995-2009. Em sete regiões metropolitanas, esse componente influencia mais na variação da pobreza do que o componente crescimento.

Apesar de o componente distribuição predominar, os resultados apontam novamente para uma distinção de períodos. Isso porque até 2002 o componente desigualdade de renda é predominante em quase todas as regiões metropolitanas. A partir de 2003, não se pode inferir com clareza a predominância de um componente, uma vez que o componente crescimento da renda é predominante em apenas duas regiões; nas demais, o comportamento da severidade da pobreza é determinado por ambos os componentes.

As decomposições da variação da pobreza feitas até aqui mostram que, em períodos distintos da economia brasileira, ocorre importante diferença no comportamento da pobreza. Em um primeiro momento, a economia brasileira apresenta uma trajetória de baixo crescimento econômico e retomada da estabilidade macroeconômica; já a pobreza aumenta em quase todas as regiões metropolitanas.

No período seguinte, com uma economia mais estável, com menores taxas de desemprego e aumento real do salário mínimo, aliada ao aumento de programas sociais destinados à parcela menos favorecida da população, a pobreza apresentou trajetória declinante. Nesse período, a elevação 
Tabela 5 Decomposição da variação da pobreza (P2) nas regiões metropolitanas

\begin{tabular}{|c|c|c|c|c|c|c|c|c|c|c|c|c|c|c|}
\hline \multirow[b]{2}{*}{$\begin{array}{l}\text { Região } \\
\text { Metropoli- } \\
\text { tana }\end{array}$} & \multirow[b]{2}{*}{ 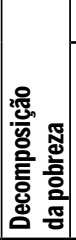 } & \multicolumn{13}{|c|}{ SEVERIDADE DA POBREZA (P2) } \\
\hline & & 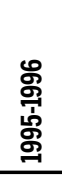 & 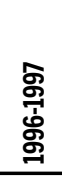 & 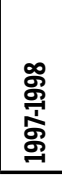 & $\begin{array}{l}\text { \% } \\
\stackrel{9}{\circ} \\
\text { \% }\end{array}$ & 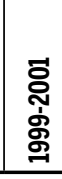 & 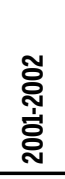 & 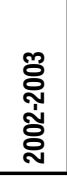 & 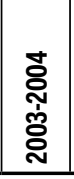 & 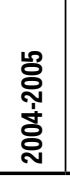 & 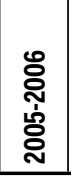 & 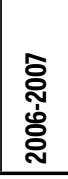 & 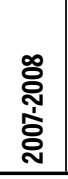 & 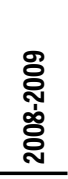 \\
\hline \multirow{3}{*}{ Belém } & $\Delta P$ & 1.62 & -1.15 & 0.47 & -0.24 & 0.62 & -0.83 & 0.69 & -1.01 & -0.61 & 0.22 & -0.85 & 0.49 & -0.62 \\
\hline & $\mathrm{EC}$ & 0.01 & 0.17 & -0.20 & 0.63 & 0.87 & -0.28 & 0.94 & -0.42 & -0.32 & 0.70 & -1.09 & 0.47 & -0.37 \\
\hline & ED & 1.61 & -1.32 & 0.67 & -0.87 & -0.25 & -0.55 & -0.25 & -0.59 & -0.29 & -0.48 & 0.24 & 0.02 & -0.25 \\
\hline \multirow{3}{*}{ Fortaleza } & $\Delta P$ & 0.52 & -0.73 & 0.38 & 0.74 & 0.2 & -2.02 & 0.84 & -0.47 & -0.54 & -0.37 & -0.66 & 0.22 & -0.56 \\
\hline & EC & -0.04 & -0.07 & 0.15 & 0.36 & -0.75 & 0.48 & 1.30 & -1.01 & -0.23 & 0.54 & -0.73 & 0.04 & -0.72 \\
\hline & ED & 0.56 & -0.66 & 0.23 & 0.38 & 0.96 & -2.50 & -0.46 & 0.54 & -0.31 & -0.91 & 0.07 & 0.18 & 0.16 \\
\hline \multirow{3}{*}{ Recife } & $\Delta P$ & 0.04 & 0.67 & -0.72 & 0.68 & -0.08 & -0.39 & 1.70 & -0.68 & -0.66 & -0.49 & -0.42 & 0.36 & -0.88 \\
\hline & EC & -0.53 & 0.33 & -0.52 & 0.43 & -0.4 & 0.06 & 1.65 & -1.11 & -0.40 & 0.46 & -0.39 & -0.10 & -0.64 \\
\hline & ED & 0.57 & 0.34 & -0.20 & 0.25 & 0.33 & -0.45 & 0.05 & 0.43 & -0.26 & -0.95 & -0.04 & 0.46 & -0.24 \\
\hline \multirow{3}{*}{ Salvador } & $\Delta P$ & 0.12 & -0.96 & 0.06 & 0.69 & -0.58 & -0.29 & 0.90 & -0.61 & -1.11 & -0.60 & -0.44 & -0.18 & -0.26 \\
\hline & EC & -0.31 & -0.41 & 0.26 & 0.31 & 0.2. & -0.26 & 1.46 & -0.38 & -0.54 & 0.02 & -0.63 & 0.02 & -0.40 \\
\hline & ED & 0.43 & -0.55 & -0.20 & 0.38 & -0.79 & -0.03 & -0.56 & -0.23 & -0.57 & -0.62 & 0.19 & -0.20 & 0.14 \\
\hline \multirow{3}{*}{$\begin{array}{l}\text { Belo } \\
\text { Horizonte }\end{array}$} & $\Delta P$ & 0.30 & -0.51 & 0.25 & -0.04 & -0.22 & -0.37 & 0.09 & -0.08 & -0.45 & -0.02 & -0.27 & -0.14 & -0.12 \\
\hline & EC & 0.04 & -0.19 & 0.18 & 0.20 & 0.11 & -0.11 & 0.32 & -0.18 & -0.20 & -0.10 & -0.13 & 0.01 & -0.18 \\
\hline & ED & 0.26 & -0.32 & 0.07 & -0.24 & -0.33 & -0.26 & -0.23 & 0.10 & -0.25 & 0.08 & -0.14 & -0.15 & 0.06 \\
\hline \multirow{3}{*}{$\begin{array}{l}\text { Rio de } \\
\text { Janeiro }\end{array}$} & $\Delta \mathrm{P}$ & 0.15 & -0.16 & -0.18 & -0.03 & 0.40 & -0.56 & 0.24 & -0.14 & -0.19 & 0.07 & -0.09 & -0.03 & -0.07 \\
\hline & $\mathrm{EC}$ & -0.14 & 0.13 & -0.07 & 0.15 & 0.02 & 0.05 & 0.07 & -0.07 & -0.06 & -0.04 & -0.06 & -0.04 & -0.08 \\
\hline & ED & 0.29 & -0.29 & -0.11 & -0.18 & 0.38 & -0.61 & 0.17 & -0.07 & -0.13 & 0.11 & -0.03 & 0.01 & 0.01 \\
\hline \multirow{3}{*}{$\begin{array}{l}\text { São } \\
\text { Paulo }\end{array}$} & $\Delta \mathrm{P}$ & 0.01 & -0.03 & 0.11 & -0.00 & 0.56 & -0.72 & 0.39 & -0.05 & -0.31 & -0.18 & -0.21 & 0.01 & 0.05 \\
\hline & $\mathrm{EC}$ & 0.01 & -0.02 & -0.04 & 0.24 & -0.04 & 0.02 & 0.26 & 0.13 & -0.29 & 0.05 & -0.11 & 0.07 & -0.05 \\
\hline & ED & 0.00 & -0.01 & 0.15 & -0.24 & 0.60 & -0.74 & 0.13 & -0.18 & -0.02 & -0.23 & -0.10 & -0.06 & 0.10 \\
\hline \multirow{3}{*}{ Curitiba } & $\Delta \mathrm{P}$ & -0.44 & -0.00 & 0.33 & 0.11 & -0.00 & -0.42 & -0.01 & -0.37 & -0.12 & -0.10 & -0.26 & 0.36 & -0.22 \\
\hline & EC & 0.02 & 0.00 & 0.02 & 0.18 & -0.07 & 0.07 & 0.29 & -0.30 & -0.07 & 0.11 & -0.21 & 0.04 & -0.04 \\
\hline & $E D$ & -0.46 & -0.00 & 0.31 & -0.07 & 0.07 & -0.49 & -0.30 & -0.07 & -0.05 & -0.21 & -0.05 & 0.32 & -0.18 \\
\hline \multirow{3}{*}{$\begin{array}{l}\text { Porto } \\
\text { Alegre }\end{array}$} & $\Delta P$ & 0.10 & -0.12 & 0.05 & 0.40 & -0.39 & -0.24 & 0.30 & -0.50 & -0.14 & 0.07 & -0.22 & -0.12 & -0.02 \\
\hline & EC & -0.02 & 0.07 & -0.06 & 0.13 & -0.05 & 0.10 & 0.12 & -0.08 & -0.11 & 0.04 & -0.03 & -0.03 & -0.04 \\
\hline & ED & 0.12 & -0.19 & 0.11 & 0.27 & -0.34 & -0.34 & 0.18 & -0.42 & -0.03 & 0.03 & -0.19 & -0.09 & 0.02 \\
\hline \multirow{3}{*}{$\begin{array}{l}\text { Distrito } \\
\text { Federal }\end{array}$} & $\Delta P$ & -0.06 & -0.42 & -0.27 & 0.60 & -0.08 & -1.33 & 0.28 & -0.01 & -0.62 & -0.19 & -0.51 & 0.31 & -0.43 \\
\hline & EC & 0.02 & -0.18 & -0.10 & 0.41 & -0.0 & -0.23 & 0.33 & -0.06 & -0.17 & -0.10 & -0.33 & 0.13 & -0.11 \\
\hline & ED & -0.08 & -0.24 & -0.17 & 0.19 & -0.07 & -1.10 & $-0,05$ & 0.05 & -0.45 & -0.09 & -0.18 & 0.18 & -0.32 \\
\hline
\end{tabular}

Fonte: Elaborada pelos autores com base nas PNADs/IBGE. 
dos rendimentos é o principal determinante, ocorrendo também melhora na distribuição da renda. Isso faz com que os indicadores de pobreza apresentem bons resultados, diminuindo de maneira considerável os níveis de pobreza.

\subsection{Decomposição espacial da pobreza}

Ao avaliar as variações de pobreza entre as regiões, é necessária uma reinterpretação da análise, uma vez que a aplicação se dá no âmbito espacial, em vez de temporal. Dessa forma, diferentemente da análise temporal que utiliza um ano-base ou ano inicial, adota-se, nesse caso, uma região de referência, sendo esta a média de todas as regiões metropolitanas entre 1995 e 2009. A escolha pela análise espacial da pobreza em dois períodos distintos visa verificar se ocorreu alteração no padrão de pobreza e do impacto de seus determinantes entre as regiões metropolitanas.

A análise do padrão espacial da pobreza no ano de 1995 (Tabela 6) mostra que as regiões localizadas no Nordeste do país são as que possuem proporção de pobres superior à média. Nessas regiões, o componente crescimento é o principal determinante, mostrando assim que os diferenciais de rendimentos dessas localidades fazem com que o nível de pobreza seja superior à média. Nas regiões onde a proporção de pobres verificada é inferior à média, há pequena predominância do componente crescimento em razão de, em quatro regiões, esse componente ser o principal determinante, enquanto, nas outras três regiões, o componente desigualdade tem maior impacto nas diferenças dos níveis de pobreza.

$O$ indicador de insuficiência média de renda $\left(P_{1}\right)$ apresenta comportamento semelhante ao $P_{0}$. Uma das diferenças diz respeito ao Rio de Janeiro e a Porto Alegre, onde o componente redistribuição é mais importante para explicar a diferença entre as regiões. Vale ressaltar que esse resultado se inverte na análise de $P_{0}$.

$\mathrm{Na}$ análise do indicador severidade da pobreza $\left(P_{2}\right)$, as regiões de Belém e do Distrito Federal apresentam um indicador superior à média das regiões. Nos outros dois indicadores anteriormente analisados, essas regiões haviam apresentado pobreza menor que a média. Esse resultado indica que a desigualdade de renda entre os pobres nessas regiões é superior à média de todas as regiões metropolitanas. 
Tabela 6 Decomposição espacial da pobreza nas regiões metropolitanas

\begin{tabular}{|c|c|c|c|c|c|c|c|}
\hline \multirow{2}{*}{$\begin{array}{l}\text { Região } \\
\text { Metropoli- } \\
\text { tana }\end{array}$} & \multirow{2}{*}{$\begin{array}{r}\text { Indicador } \\
\text { de } \\
\text { pobreza }\end{array}$} & \multicolumn{3}{|c|}{1995} & \multicolumn{3}{|c|}{2009} \\
\hline & & $\Delta \mathbf{P}$ & EC & ED & $\Delta \mathbf{P}$ & EC & ED \\
\hline \multirow{3}{*}{ Belém } & P0 & -0.16 & 2.38 & -2.54 & 1.78 & 5.00 & -3.22 \\
\hline & P1 & -0.14 & 0.68 & -0.84 & 0.44 & 1.57 & -1.14 \\
\hline & P2 & 0.07 & 0.32 & -0.25 & 0.17 & 0.77 & -0.60 \\
\hline \multirow{3}{*}{ Fortaleza } & P0 & 9.92 & 10.59 & -0.67 & 4.85 & 5.43 & -0.58 \\
\hline & P1 & 3.74 & 4.08 & -0.34 & 1.76 & 1.78 & -0.02 \\
\hline & P2 & 2.08 & 2.02 & 0.06 & 0.96 & 0.92 & 0.04 \\
\hline \multirow{3}{*}{ Recife } & PO & 8.17 & 11.00 & -2.83 & 5.69 & 5.36 & 0.33 \\
\hline & P1 & 2.55 & 4.13 & -1.58 & 2.44 & 1.78 & 0.66 \\
\hline & P2 & 1.04 & 2.08 & -1.04 & 1.48 & 0.94 & 0.54 \\
\hline \multirow{3}{*}{ Salvador } & PO & 8.83 & 6.45 & 2.38 & 3.27 & 2.35 & 0.92 \\
\hline & P1 & 4.03 & 2.66 & 1.37 & 1.09 & 0.80 & 0.29 \\
\hline & P2 & 2.47 & 1.40 & 1.07 & 0.54 & 0.39 & 0.15 \\
\hline \multirow{3}{*}{$\begin{array}{l}\text { Belo } \\
\text { Horizonte }\end{array}$} & P0 & -1.67 & 0.53 & -2.20 & -2.13 & -0.64 & -1.49 \\
\hline & P1 & -0.60 & 0.28 & -0.88 & -0.87 & -0.17 & -0.70 \\
\hline & P2 & -0.24 & 0.14 & -0.38 & -0.50 & -0.08 & -0.42 \\
\hline \multirow{3}{*}{$\begin{array}{l}\text { Rio de } \\
\text { Janeiro }\end{array}$} & P0 & -3.73 & -1.99 & -1.74 & -2.03 & -1.22 & -0.81 \\
\hline & P1 & -1.84 & -0.47 & -1.37 & -0.88 & -0.32 & -0.56 \\
\hline & P2 & -1.23 & -0.23 & -1.00 & -0.49 & -0.14 & -0.35 \\
\hline \multirow{3}{*}{$\begin{array}{l}\text { São } \\
\text { Paulo }\end{array}$} & PO & -6.83 & -2.98 & -3.85 & -3.04 & -0.99 & -2.05 \\
\hline & P1 & -2.56 & -1.02 & -1.54 & -0.97 & -0.21 & -0.76 \\
\hline & P2 & -1.43 & -0.49 & -0.94 & -0.48 & -0.10 & -0.38 \\
\hline \multirow{3}{*}{ Curitiba } & PO & -4.75 & -2.72 & -2.03 & -4.43 & -1.66 & -2.77 \\
\hline & P1 & -1.77 & -0.92 & -0.85 & -1.46 & -0.47 & -0.99 \\
\hline & P2 & -0.97 & -0.44 & -0.53 & -0.78 & -0.23 & -0.55 \\
\hline \multirow{3}{*}{$\begin{array}{l}\text { Porto } \\
\text { Alegre }\end{array}$} & P0 & -4.26 & -2.52 & -1.74 & -3.03 & -1.02 & -2.01 \\
\hline & P1 & -1.73 & -0.79 & -0.96 & -1.07 & -0.27 & -0.80 \\
\hline & P2 & -1.08 & -0.37 & -0.71 & -0.61 & -0.13 & -0.48 \\
\hline \multirow{3}{*}{$\begin{array}{l}\text { Distrito } \\
\text { Federal }\end{array}$} & PO & -2.79 & -4.95 & 2.16 & -2.73 & -5.26 & 2.53 \\
\hline & P1 & -0.08 & -1.73 & 1.65 & -1.23 & -1.84 & 0.61 \\
\hline & P2 & 0.66 & -0.81 & 1.47 & -0.74 & -0.89 & 0.15 \\
\hline
\end{tabular}

Fonte: Elaborada pelos autores com base nas PNADs/IBGE. 
De acordo com resultados encontrados para o ano de 2009 (Tabela 3), as regiões metropolitanas situadas no Norte e no Nordeste do país são as que apresentam proporção de pobres mais elevada que a média, também sendo o componente crescimento da renda o que mais explica a diferença. Em Belém, a menor desigualdade minimiza os efeitos negativos da renda; os resultados mostram que, se essa região metropolitana possuísse o mesmo nível de renda da média, a pobreza seria 3,22 pontos percentuais menor. Em Fortaleza também se verifica tal fato, mas em uma proporção menor.

$\mathrm{Na}$ maioria das regiões onde a pobreza verificada é inferior à média, o componente redistribuição é o determinante dessa diferença. As exceções são o Distrito Federal e o Rio de Janeiro, onde o melhor nível de renda compensa a maior desigualdade de renda.

Nos outros dois indicadores de pobreza analisados - insuficiência média de renda $\left(P_{1}\right)$ e severidade da pobreza $\left(P_{2}\right)$-, a tendência verificada é semelhante àquela do indicador anterior. Somente no Rio de Janeiro há alteração em relação à predominância dos componentes, ou seja, no primeiro indicador o componente crescimento da renda é o determinante mais importante das diferenças nos níveis de pobreza, ao passo que, nos dois últimos indicadores, o determinante mais importante é o componente redistribuição.

É possível verificar na análise espacial de decomposição da pobreza em dois períodos distintos diminuição das diferenças regionais, uma vez que a distância dos índices de pobreza para a média diminuiu na grande maioria das regiões. $O$ componente crescimento se manteve predominante durante todo o período analisado nas regiões onde a pobreza é mais elevada. Isso indica que a renda mais baixa dessas regiões é a principal causa do maior nível de pobreza em comparação à média das regiões metropolitanas.

Dessa forma, nota-se alteração do padrão espacial da pobreza nas regiões metropolitanas. Comparativamente às políticas direcionadas à melhoria na distribuição de renda, as políticas voltadas para a elevação surtiriam mais efeito nas regiões mais afetadas pela pobreza.

\section{Considerações finais}

Este artigo tem por objetivo principal analisar o comportamento da pobreza nas regiões metropolitanas tendo por base seus dois macrodeterminantes imediatos: crescimento econômico e desigualdade de renda. A pobreza tratada nes- 
te estudo sob o âmbito unidimensional de privação de renda foi calculada por meio da família de índices FGT, utilizando a linha de pobreza de R $\$ 140,00$.

Para se alcançar o objetivo indicado, utilizou-se a decomposição temporal (realizada anualmente) e espacial de Shapley, metodologia esta proposta por Shorrocks (1999). Tal metodologia permite captar os desvios dos níveis de pobreza, sendo esses desvios atribuídos a três fontes: renda média per capita, desigualdade e linha de pobreza.

Os resultados encontrados apresentam significativas diferenças durante todo o período analisado, tanto para a trajetória da pobreza como para o seu comportamento diante de seus determinantes imediatos.

No período de 1995 a 2003, os indicadores de pobreza se elevaram na maioria das regiões analisadas. As regiões metropolitanas localizadas no Nordeste - Salvador, Recife e Fortaleza - são as que apresentaram maior proporção de pobres, sendo Fortaleza a região com mais elevado nível de pobreza dentre as dez regiões analisadas.

Dado tal comportamento da pobreza, os exercícios de decomposição ajudaram a explicar quais são os determinantes dessa trajetória. No período de 1995-2003, o componente redistribuição foi determinante para explicar a trajetória da pobreza na maioria das regiões metropolitanas. Importante citar que, apesar de não ser o principal determinante, o componente crescimento também contribuiu para o aumento da pobreza.

Esses resultados negativos se referem a um momento específico das economias brasileira e internacional. Em um contexto de crises externas, trajetória de baixo crescimento econômico e elevação da taxa de desemprego, os níveis de pobreza se elevam.

O período de 2004 a 2009 se mostrou distinto do anterior, visto que os níveis de pobreza diminuíram em todas as regiões metropolitanas, e os resultados da decomposição se alteraram. Nesse período, o crescimento da renda foi determinante na explicação da trajetória declinante da pobreza, não obstante a melhora na distribuição de renda também ter ocorrido em todas as regiões. Essa evolução nos indicadores pode ter se beneficiado do momento estável pelo qual passava a economia na época, com menores taxas de desemprego, aumento real do salário mínimo e aumento de programas sociais destinados à parcela menos favorecida da população.

A respeito da análise espacial de decomposição da pobreza, verificou-se diminuição das diferenças de pobreza entre as regiões metropolitanas. Os determinantes dessa variação pouco se alteraram. $O$ crescimento continua 
sendo o determinante principal nas regiões onde a pobreza é mais elevada. Isso indica que a renda mais baixa dessas regiões é a principal causa do maior nível de pobreza.

\section{Referências}

ARAÚJO, T. F. As inter-relações entre pobreza, desigualdade e crescimento nas mesorregiões mineiras, 1970-2000. Dissertação (Mestrado em Economia) - Universidade Federal de Minas Gerais, Belo Horizonte, 2007.

BARRETO, F. A.; FRANÇA, J. M.; OLIVEIRA, V. H. O que mais importa no combate à pobreza, crescimento da renda ou redução da desigualdade? Evidências para as regiões brasileiras. Fortaleza, CE: UFC/CAEN/LEP, 2008. (Ensaio sobre pobreza, 16)

BARROS, R. P.; CARVALHO, M.; FRANCO, S.; MENDONCA, R. A importancia da queda recente da desigualdade na reducao da pobreza. Texto para Discussão $n^{\circ} 1.256$. Rio de Janeiro: IPEA, 2007.

BARROS, R. P.; CARVALHO, M.; FRANCO, S.; MENDONÇA, R. Consequências e causas imediatas da queda recente da desigualdade de renda brasileira. Rio de Janeiro: IPEA, 2006.

BARROS, R. P.; HENRIQUES, R.; MENDONÇA, R. Desigualdade e pobreza no Brasil: Retrato de uma estabilidade inaceitável. Revista Brasileira de Ciências Sociais, v. 15, n. 42, p. 123-142, 2000.

BAYE, F. M. Growth and redistribution effects of poverty changes in Cameroon: A shapley decomposition analysis. In: AFRICAN DEVELOPMENT AND POVERTY REDUCTION: THE MACRO-MICRO LINKAGE, 2004, Cape Town. Forum paper. Somerset West, South Africa, 2004.

CHOW, G. C. Tests of equality between sets of coefficients in two linear regressions. Econometrica, v. 26, p. 591-605, 1960.

CORSEUIL, C. H.; FOGUEL, M. N. Uma sugestao de deflatores para rendas obtidas a partir de algumas pesquisas domiciliares do IBGE. Texto para Discussão $n^{\circ} 894$. Rio de Janeiro: IPEA, 2002.

DATT, G.; RAVALLION, M. Growth and redistribution components of changes in poverty measures. Journal of Development Economics, v. 38, n. 2, p. 275-295, Apr. 1992.

FOSTER, J.; GREER, J.; THORBECKE, E. A class of decomposable poverty measures. Econometrica, v. 52, n. 3, p. 761-768, May 1984.

KAKWANI, N. On measuring growth and inequality components of changes in poverty with application to Thailand. Sydney: The University of New South Wales, 1997.

KOLENIKOV, S.; SHORROCKS, A. A decomposition analysis of regional poverty in Russia. Discussion Paper, n. 74. World Institute for Development Economics Research, 2003.

MANSO, C. A.; BARRETO, F. A.; TEBALDI, E. O desequilíbrio regional brasileiro: Novas perspectivas a partir das fontes de crescimento "Pró-Pobre". Revista Econômica do Nordeste, v. 37, n. 3, p. 307-328, jul.-set. 2006. 
MARINHO, E.; SOARES, F. Impacto do crescimento econômico e da concentração de renda sobre a redução da pobreza nos estados brasileiros. In: ENCONTRO NACIONAL DE ECONOMIA, 31., 2003, Porto Seguro, BA. Anais...Belo Horizonte: ANPEC, 2003.

MATIAS, J. S.; SALVATO, M. A.; BARRETO, F. A. F. D. Análise da qualidade do crescimento econômico nos estados brasileiros de 1995 a 2008: Quão elásticos são os indicadores de pobreza relativos ao crescimento? In: ENCONTRO NACIONAL DE ECONOMIA, 38., 2010, Salvador. Anais... Salvador: Associação Nacional dos Centros de Pós-Graduação em Economia (ANPEC), 2010.

MAZUMDAR, D.; SON, H. H. Vulnerable groups and the labor market in Thailand: Impact of the Asian financial crisis in the light of Thailand's growth process. In: CONFERENCE IN HONOUR OF PROFESSOR ALBERT BERRY. Anais... University of Toronto. Forum Paper, Toronto, 2002.

MÜLLER, A. Clarifying poverty decomposition. In: GERMAN DEVELOPMENT ECONOMICS CONFERENCE. Anais... Conference Paper, Zürich, 2008.

NEDER, H. D.; SILVA, J. L. M. Pobreza e distribuição de renda em áreas rurais: Uma abordagem de inferência. Revista de Economia e Sociologia Rural, v. 42, n. 30, p. 469-486, jul.-set. 2004.

ROCHA, S. Crescimento, renda e pobreza. Como ficam os pobres? In: FÓRUM NACIONAL - NA CRISE, BRASIL, DESENVOLVIMENTO DE UMA SOCIEDADE ATIVA E MODERNA (SOCIEDADE DO DIÁlOGO, DA TOLERÂNCIA, DA NEGOCIAÇÃO), 22., 2010, Rio de Janeiro. Anais... Rio de Janeiro, Programa Nacional de Direitos Humanos. E Novos Temas. Rio de Janeiro, 2010.

ROCHA, Sonia. Pobreza no Brasil: Afinal, de que se trata? 3. ed. Rio de Janeiro: FGV, 2006.

SEN, A. Poverty: An ordinal approach to measurement. Econometrica, v. 44, n. 2, p. 219-231, 1976.

SHORROCKS, A. F. Decomposition procedures for distributional analysis: A unified framework based on the Shapley value. University of Essex, 1999. (Mimeogr.)

TODARO, M. P.; SMITH, S. C. Economic Development. 10th ed. New York: Person, 2009.

ZHANG, Yin; WAN Guanghua. Why do poverty rates differ from region to region? The case of urban China. WIDER Research Paper; 2005/56. Helsinki: United Nations University/ Wider, 2005.

\section{Sobre os autores}

Douglas Mesquita Carneiro - douglasmcarneiro@hotmail.com

Doutorando em Economia, Programa de Pós-Graduação em Economia, PUCRS, Porto Alegre, RS.

Izete Pengo Bagolin - izete.bagolin@pucrs.br

Professora e pesquisadora da Faculdade de Administração, Contabilidade e Economia, Programa de Pós-Graduação em Economia, PUCRS, Porto Alegre, RS.

Silvio Hong Tïng Tai - silvio.tai@pucrs.br

Professor e pesquisador da FACE, Programa de Pós-Graduação em Economia, PUCRS, Porto Alegre, RS.

\section{Sobre o artigo}

Recebido em 22 de maio de 2013. Aprovado em 6 de novembro de 2014. 


\section{APÊNDICE}

\section{Testes de ruptura estrutural}

O teste de $\mathrm{Chow}^{8}$ é utilizado para a verificação de mudança estrutural nos parâmetros em determinado período de tempo, sendo possível assim fazer inferência estatística a respeito dos diferentes padrões de comportamento da pobreza entre períodos.

A Tabela A1 mostra os valores do teste $\mathrm{F}$ e os $p$ valores para o teste de Chow em uma regressão do índice $P O$ na variável ano. São considerados dois períodos: um período anterior ao ano considerado e um período posterior. ${ }^{9}$ Os valores mais elevados do teste F indicam maior possibilidade de se rejeitar a hipótese nula, segundo a qual o coeficiente da variável ano é igual nos dois períodos.

Tabela A1 Estatísticas do teste de Chow

\begin{tabular}{l|r|r|r|r|r|r|r|r|r}
\hline & $\mathbf{1 9 9 7}$ & $\mathbf{1 9 9 8}$ & $\mathbf{1 9 9 9}$ & $\mathbf{2 0 0 1}$ & $\mathbf{2 0 0 2}$ & $\mathbf{2 0 0 3}$ & $\mathbf{2 0 0 4}$ & $\mathbf{2 0 0 5}$ & $\mathbf{2 0 0 6}$ \\
\hline Teste F & 1.59 & 2.64 & 4.46 & 5.19 & 5.52 & 6.08 & 6.09 & 5.94 & 4.28 \\
\hline p valor & 0.2080 & 0.0748 & 0.0133 & 0.0067 & 0.0050 & 0.0030 & 0.0029 & 0.0034 & 0.0158 \\
\hline
\end{tabular}

Fonte: Elaborada pelos autores com base nas PNADs/IBGE.

As regressões recursivas do índice Po na variável ano foram estimadas com três "janelas" de tempo diferentes. Estimou-se com "janelas" de quatro, cinco e seis anos. ${ }^{10} \mathrm{O}$ Gráfico $\mathrm{A} 1$, a seguir, apresenta os resultados dessas regressões.

8 Chow (1960).

9 O período posterior inclui o ano considerado.

10 Para ilustrar, com uma "janela" de tempo de quatro anos, estimou-se 11 regressões representadas no primeiro painel do Gráfico 1: de 1995 a 1998, de 1996 a 1999, de 1997 a 2001, de 1998 a 2002, de 1999 a 2003, de 2001 a 2004, de 2002 a 2005, de 2003 a 2006, de 2004 a 2007, de 2005 a 2008 e de 2006 a 2009. 


\section{Gráfico A1 Regressão recursiva de quatro, cinco e seis anos, respectivamente}
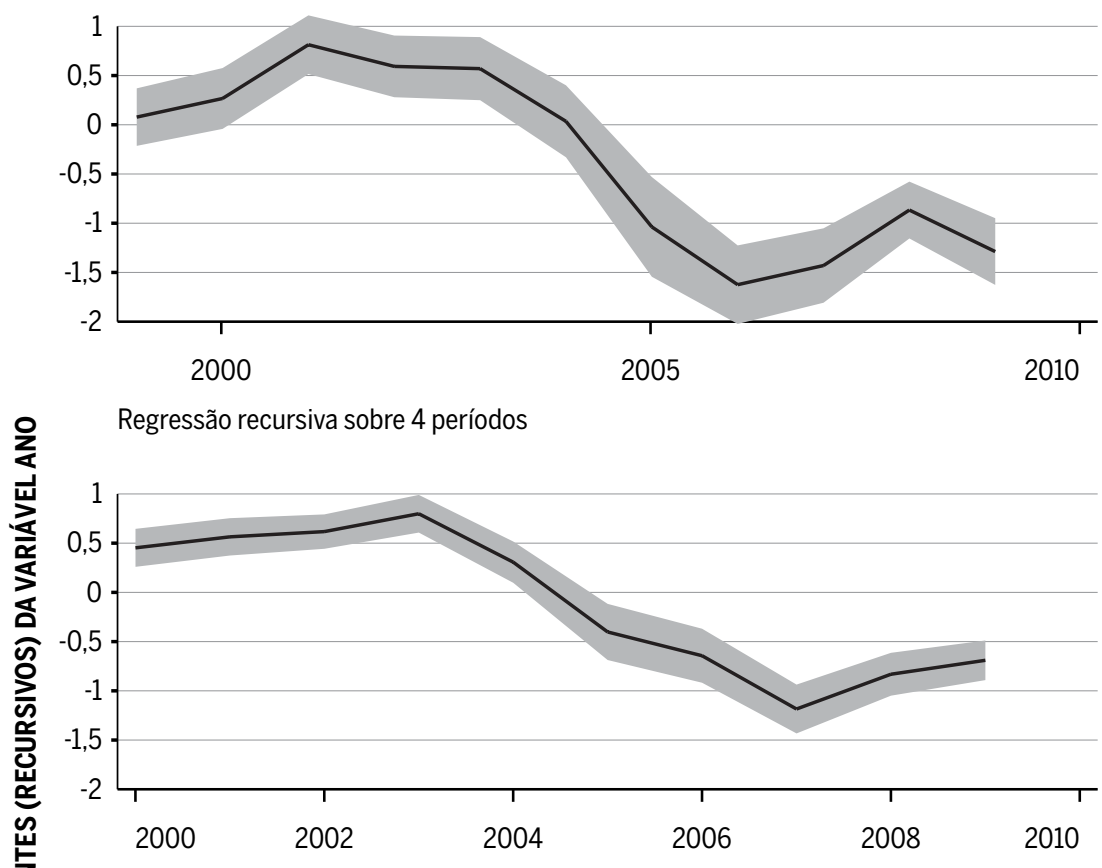

总

Regressão recursiva sobre 5 períodos

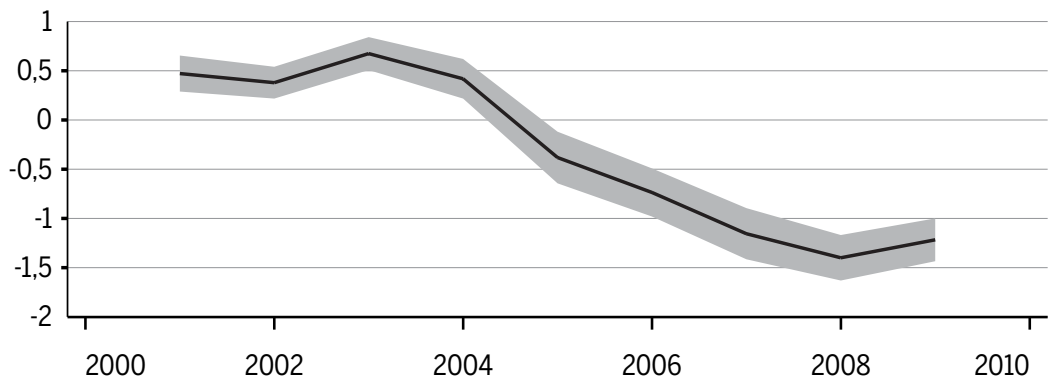

Regressão recursiva sobre 6 períodos

ANO

Fonte: Elaborado pelos autores com base nas PNADs/IBGE.

Nota: A área sombreada corresponde ao intervalo de confiança de 95\% do coeficiente da variável ano. 